\title{
Morphological particularities and morphometry of rats' kidneys under the effect of experimental mild traumatic brain injury
}

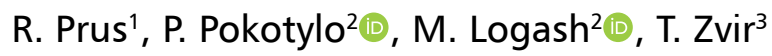 \\ ${ }^{1}$ Department of Pathological Anatomy with Section Course, Odessa National Medical University, Odessa, Ukraine \\ 2Department of Normal Anatomy, Danylo Halytsky Lviv National Medical University, Lviv, Ukraine \\ ${ }^{3}$ Liaison Librarian, the Catholic University of America, Washington, United States
}

[Received: 18 February 2020; Accepted: 7 April 2020]

Background: Traumatic brain injury (TBI) is one of the most serious problems of modern medicine that plays the dominant role in the morbidity and mortality of population of the economically developed countries. This article presents the findings of the experimental study of the effect of a mild TBI on the morphology of rats' kidney.

Materials and methods: The experiment was performed on 70 adult white rats 3 months of age. The mild TBI was modelled by the Impact-Acceleration Model free fall of weight in the parieto-occipital area. For histopathological comparison, the samples were taken on the $1^{\text {st }}, 3^{\text {rd }}, 5^{\text {th }}, 7^{\text {th }}, 14^{\text {th }}, 21^{\text {st }}$ days after TBI.

Results: Examination of the rat's kidney histological slides on the $1^{\text {st }}, 3^{\text {rd }}, 5^{\text {th }}, 7^{\text {th }}$, $14^{\text {th }}$, and $21^{\text {st }}$ days after the TBI showed manifested changes in the bloodstream and structural changes in the kidney parenchyma, particularly, dilatation of the capillaries and veins in the initial period. It also showed perivascular lymphocytic infiltration, dystrophic and necrotic processes in the form of the focal destruction of the renal tubule, and renal corpuscles with diapedesis and perivascular haemorrhages on the $5^{\text {th }}$ and $7^{\text {th }}$ days after the TBI. There were also the focal signs of perivascular and glomerular sclerosis observed on the $14^{\text {th }}$ and $21^{\text {st }}$ days after the injury.

Conclusions: The greatest changes in the rats' kidneys appear on the $5^{\text {th }}-7^{\text {th }}$ days after the injury, which have a clear tendency to decrease after that. (Folia Morphol 2021; 80, 2: 310-316)

Key words: traumatic brain injury, kidney, rat, nephron

\section{INTRODUCTION}

Traumatic brain injury (TBI) is one of the most important problems of modern medicine, which plays a major role in the morbidity and mortality of the population even in the most economically developed countries $[3,7,8,10,11,20,23,25,26]$. This medical problem is multidisciplinary in the field of practical and experimental medicine and biology, which, in addition to medical, has an important social significance, given the young age of patients traumatized, and the significant cost of their treatment $[9,24]$. 
Traumatic brain injury has a global effect on the body, causing a general adaptive response, which is manifested by a complex of pathophysiological and pathomorphological changes not only in the area of direct mechanical damage but also in various organs and systems of the body, in particular in the kidneys $[4,5]$. Currently, there is a small amount of experimental research that would reveal the content of morphological disorders of the internal organs of pubescent and immature rats due to TBI, especially in the advanced period. As for the paediatric TBI, it is known that a distinctive feature of the dynamics and clinical picture of TBI in children is the impact of a traumatic factor on the brain, the growth and development of which has not yet completed [6]. In addition, the intensity of metabolic processes, low tolerance to blood loss, hypoxia and hypotension, prevalence of generalised reactions over local, high compensatory opportunities with a fast transition to decompensation, should be taken into account in a case of TBI in children [22]. This is the reason why the TBls of even mild severity caused in childhood do not go away without a trace.

It has been shown that in severe TBI, especially in its acute period, liver and renal failure are among the most common disorders, as well as individual disorders in the coronary vessels and myocardium [15]. Extracranial complications, including acute kidney injury, are highly influential in determining the outcome from severe head injury $[2,12,13,17,19]$ and may contribute to morbidity and mortality. However, there is neither a clear understanding of the pathogenesis of such effects nor experimental work that would confirm or refute the assumption of morphological changes in the kidney, as a result of TBI, particularly - mild TBI. The purpose of this study was to reveal the content of internal organ morphology, particularly the kidneys, in rats affected by TBI of mild severity with particular focus on pubescent rats. Thus, the first stage of this study was to investigate such changes in pubescent rats immediately after the injury and in the more advanced period after the injury.

\section{MATERIALS AND METHODS}

The study was performed on 70 adult white rats aged 3 months with the bodyweight of $180-230 \mathrm{~g}$. All animals were divided into two groups: 1 - healthy animals (control group, 10 animals), 2 - animals with simulated mechanical TBI of mild severity (60 animals). Animals in group 2 were removed from the experiment on days $1,3,5,7,14$, and 21 after the TBI modelling (10 animals on each day). Rats were kept on a standard laboratory diet with free unrestricted access to water at the vivarium of the Odessa National Medical University. All experiments were carried out in compliance with the provisions of the European Convention for the Protection of Vertebrate Animals used for research and other scientific purposes (Strasbourg, 18.03.1986), Council of Europe Directive 86/609/EEC (1986), resolutions of the First National Congress on Bioethics (Kyiv, 2001), and the Ministry of Health of Ukraine Order No. 690 (Kyiv, 23.09.2009). All stages of the experiments were approved by the ONMEDU Bioethics Commission (Minutes No. 109-A, 4.11. 2016). Mild TBI was inflicted by using the Impact-Acceleration Model, a free fall of weight onto the parieto-occipital area according to Meretskyi [16]. Reproduction of TBI a vertically mounted tripod metal guide tube was used with an inner diameter of $1 \mathrm{~mm}$ and a height of $65 \mathrm{~cm}$. The tube served as a guide for a freely moving weight inside. The latter represented a circular metal rod, to which a solid rubber strip $3 \mathrm{~mm}$ thick and $0.5 \mathrm{~cm}^{2}$ in area was glued to the lower end. The tripod stand was also glued with a sturdy rubber gasket. By means of light ether anaesthesia, the animals were placed under the tube so that the head was clearly below the opening and fixed by the experimenter. Then the tractor performed a free fall with a subsequent blow to the skull of the animal. Thus, the centre of impact was clearly on the sagittal line forward 3-5 $\mathrm{mm}$ from the intrauricular line. For reproduction of the TBI of a mild severity in mature rats, a $34.5 \mathrm{~g}$ tractor was used, which produced impact energy of $0.220 \mathrm{~J}$. The animals were removed from the experiment by an overdose of ether anaesthesia, after which the kidney samples were prepared and obtained for further histological examination. Histological slides were stained with the haematoxylin and eosin and Mallory's trichrome, examined, and photographed using the Leica-DMLS microscope while all the measurements were done with the ImageJ software (ver.1.51j8).

\section{Statistical analysis}

The obtained results were tested for the normality of distribution with Shapiro-Wilk test. All the data were presented as $\mathrm{M} \pm \mathrm{SD}$ where " $\mathrm{M}$ " stands for average and "SD" for standard deviation. The differences between the groups were analysed using analysis of variance (ANOVA) with Tukey's post-hoc test. The 


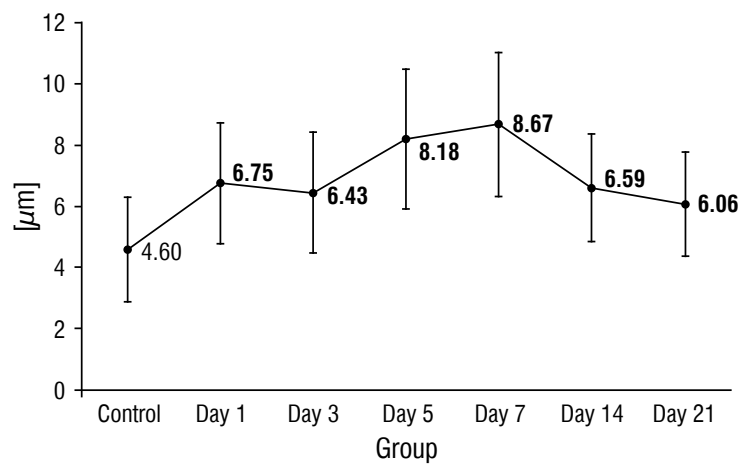

Figure 1. Diameter variation of the rats' peritubular capillaries.

Table 1. Rats' nephron glomerulus measurements

\begin{tabular}{lcccccc}
\hline Group & Mean & SD & SEM & Min & Max & N \\
\hline Control & 66.46 & 10.57 & 1.53 & 48.33 & 90.69 & 48 \\
Day 1 & 67.76 & 14.15 & 2.24 & 44.57 & 95.95 & 40 \\
Day 3 & 74.24 & 10.74 & 1.87 & 50.65 & 93.50 & 33 \\
Day 5 & $76.85^{*}$ & 15.19 & 2.11 & 48.77 & 105.35 & 52 \\
Day 7 & $77.78^{* *}$ & 15.31 & 2.12 & 49.02 & 105.49 & 52 \\
Day 14 & $76.23^{*}$ & 10.52 & 1.66 & 57.71 & 97.55 & 40 \\
Day 21 & 73.97 & 10.23 & 1.62 & 54.10 & 95.99 & 40 \\
\hline
\end{tabular}

${ }^{*} p<0.05,{ }^{* *} p<0.001$; SD — standard deviation; SEM — standard error of mean;

$\mathrm{Min}$ - minimum value; Max — maximum value; $\mathrm{N}$ - total numbers of measurements

differences turned out to be statistically significant with the $p$-value $<0.05$. All statistical computing was done with the RStudio software (ver. 1.1.442).

\section{RESULTS}

After the TBI modelling, no fatalities, behavioural, or dietary changes were recorded in the animals. On the $1^{\text {st }}$ day after the inflicted experimental injury, hyperaemia of the tubular capillaries with the stasis of erythrocytes in their lumen in all examined histological specimens was observed. The mean diameter increased up to $6.75 \pm 1.98 \mu \mathrm{m}$ (index of the control group $4.60 \pm 1.72 \mu \mathrm{m}, \mathrm{p}<0.001$; Fig. 1) while the diameter of the dilated afferent arterioles was in the range of $10-15 \mu \mathrm{m}$. Some veins were dilated with the stasis of erythrocytes in their lumen with 40-60 $\mu \mathrm{m}$ in diameter. Erythrocytic stasis was also observed in the lumen of the medium-sized arteries. Nephron glomeruli were fragmented, and their diameter remains in the range of control group value, as well as the capsule diameter (Tables 1, 2). Capillaries of glomeruli had narrowed down to $2.44 \mu \mathrm{m}$ and dilated - with the maximal value up to $9.91 \mu \mathrm{m}$ as opposed to the control group where the maximal value remained at

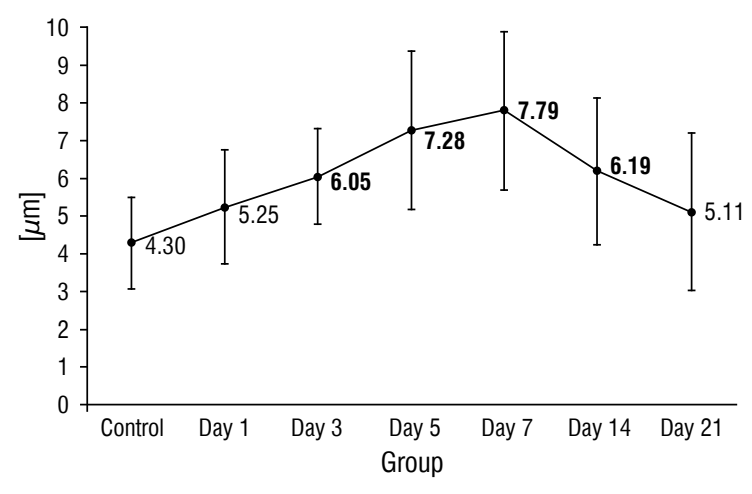

Figure 2. Diameter variation of the rats' glomerular capillaries.

Table 2. Rats' nephron capsule measurements

\begin{tabular}{lcccccc}
\hline Group & Mean & SD & SEM & Min & Max & N \\
\hline Control & 79.90 & 12.30 & 2.32 & 63.23 & 112.81 & 28 \\
Day 1 & 86.55 & 12.89 & 2.06 & 58.43 & 120.63 & 39 \\
Day 3 & 90.14 & 10.90 & 1.99 & 70.38 & 114.85 & 30 \\
Day 5 & $93.07^{*}$ & 14.76 & 1.97 & 62.85 & 122.43 & 56 \\
Day 7 & $94.06^{*}$ & 14.82 & 1.98 & 63.47 & 123.14 & 56 \\
Day 14 & 85.20 & 11.85 & 1.87 & 66.73 & 115.24 & 40 \\
Day 21 & 83.20 & 11.87 & 1.88 & 66.39 & 112.74 & 40 \\
\hline
\end{tabular}

${ }^{*} \mathrm{p}<0.001 ; \mathrm{SD}$ - standard deviation; SEM — standard error of mean; Min — minimum value; Max - maximum value; $\mathrm{N}$ - total numbers of measurements

$7.80 \mu \mathrm{m}$. The mean value was $5.25 \pm 1.51 \mu \mathrm{m}$ (Fig. 2), which is significantly higher than of the control group $(p<0.05)$.

On the $3^{\text {rd }}$ day of the experiment, in all of the samples dilatation of the tubular capillaries with erythrocytic stasis in their lumen continued to persist. Their diameter in certain areas was up to $12.12 \mu \mathrm{m}$ with the mean value of $6.43 \pm 1.98 \mu \mathrm{m}$, the diameter of glomerular capillaries increased too (Table 3). Erythrocytic stasis was observed in the veins of all calibres with their dilatation in separate areas reaching up 40-50 $\mu \mathrm{m}$. This was especially the case for the area between the cortical layer and the medullary area. Dilatation of vasa recta was also observed with diameter reaching up to $12-15 \mu \mathrm{m}$ with erythrocytic stasis in their lumen.

On the $5^{\text {th }}$ and $7^{\text {th }}$ days of the TBI, renal corpuscles of various sizes were observed in the majority of examined specimens. The diameter of the glomerulus on the $5^{\text {th }}$ day was $76.85 \pm 15.19 \mu \mathrm{m}$ and $77.78 \pm$ $\pm 15.31 \mu \mathrm{m}$ on the $7^{\text {th }}$ day. The diameter of the capsule of the renal corpuscle also had reached its maximal value $-93.07 \pm 14.76 \mu \mathrm{m}$ on the $5^{\text {th }}$ day and $94.06 \pm 14.82 \mu \mathrm{m}$ on the $7^{\text {th }}$ day. The diameter of 
Table 3. Measurements of glomerular capillaries.

\begin{tabular}{lcccccc}
\hline Group & Mean & SD & SEM & Min & Max & N \\
\hline Control & 4.30 & 1.22 & 0.17 & 2.41 & 7.80 & 52 \\
Day 1 & 5.25 & 1.51 & 0.18 & 2.44 & 9.91 & 70 \\
Day 3 & $6.05^{*}$ & 1.29 & 0.14 & 4.09 & 11.93 & 82 \\
Day 5 & $7.28^{*}$ & 2.10 & 0.26 & 3.44 & 12.68 & 67 \\
Day 7 & $7.79^{*}$ & 2.12 & 0.26 & 3.91 & 13.11 & 67 \\
Day 14 & $6.19^{*}$ & 1.94 & 0.23 & 3.09 & 15.92 & 73 \\
Day 21 & 5.11 & 2.08 & 0.25 & 1.82 & 15.03 & 72 \\
\hline
\end{tabular}

${ }^{*} \mathrm{p}<0.001$; SD — standard deviation; SEM — standard error of mean; Min — minimum value; Max — maximum value; $\mathrm{N}-$ total numbers of measurements

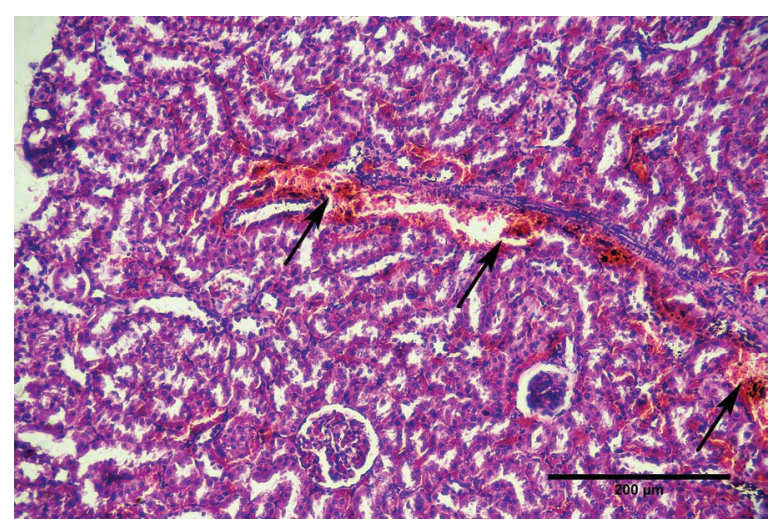

Figure 3. Perivascular haemorrhage (arrow); $5^{\text {th }}$ day after traumatic brain injury; haematoxylin and eosin.

the tubular capillaries and capillaries of the nephron glomeruli had reached their maximum throughout the experiment on the $7^{\text {th }}$ day (Figs. 1, 2, Tables 3, 4). This was predominantly due to dilatation of the cortical capillaries that were close to the renal capsule while the diameter of some capillaries was $15.46 \mu \mathrm{m}$. In some places, renal corpuscles were partially destroyed and there was a dilation of the space between the glomeruli and the capsule. Small arteries were congested, mainly, with aggregated erythrocytes (sludge). Perivascular space showed impregnation of the blood cells and massive lymphocytic infiltrates with perivascular haemorrhage in some areas (Fig. 3). The renal medulla showed the areas with the signs of renal infarction and destruction of the proximal and distal tubules. One of the characteristic features of this period was dilatation of the arcuate veins with the blood stasis in their lumen, the diameter of which reached $50-80 \mu \mathrm{m}$.

On the $14^{\text {th }}-21^{\text {st }}$ days after the TBI the sclerotic changes of the renal corpuscles were focally observed (Fig. 4) as well as the massive perivascular infiltrates
Table 4. Measurements of tubular capillaries

\begin{tabular}{lcccccc}
\hline Group & Mean & SD & SEM & Min & Max & N \\
\hline Control & 4.60 & 1.72 & 0.29 & 1.14 & 7.78 & 36 \\
Day 1 & $6.75^{* *}$ & 1.98 & 0.27 & 2.98 & 11.84 & 53 \\
Day 3 & $6.43^{* *}$ & 1.98 & 0.23 & 2.63 & 12.12 & 72 \\
Day 5 & $8.18^{* *}$ & 2.30 & 0.23 & 4.09 & 15.46 & 97 \\
Day 7 & $8.67^{* *}$ & 2.36 & 0.24 & 4.25 & 16.32 & 97 \\
Day 14 & $6.59^{* *}$ & 1.75 & 0.20 & 3.00 & 12.52 & 80 \\
Day 21 & $6.06^{*}$ & 1.73 & 0.19 & 2.34 & 11.96 & 80 \\
\hline
\end{tabular}

${ }^{*} p<0.05,{ }^{* *} p<0.001 ; S D$ - standard deviation; SEM — standard error of mean; Min - minimum value; Max — maximum value; $\mathrm{N}$ - total numbers of measurements

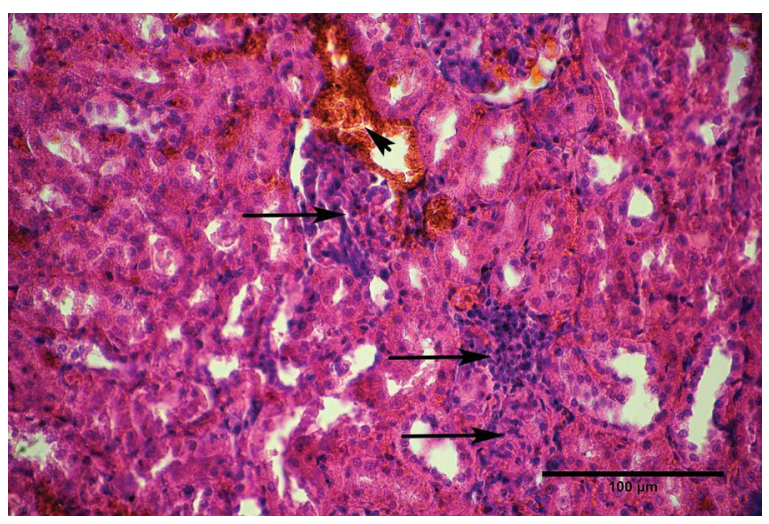

Figure 4. Destruction of renal corpuscle with lymphocytic infiltrate and sclerosis (arrow). Blood clot near renal corpuscle (arrowhead); $14^{\text {th }}$ day after traumatic brain injury; haematoxylin and eosin.

and initial signs of sclerosing of perivascular spaces in the renal medulla (Fig. 5). Infiltrates were observed in all specimens, while the signs of sclerosis were detected in 6 animals. The renal corpuscles focally were fragmented with infiltrates taking their place and the signs of formation of the connective tissue (Figs. 4, 6). Lumen of the vessels, especially veins, was filled with the red blood cells occasionally sticking to their intima. The diameter of capillaries and the size of glomeruli tended to decrease, though all their values remained significantly greater than those of the control group. Venous dilatation and blood cells aggregation were especially manifested in the area between the renal cortex and the medulla similarly to the previous periods.

\section{DISCUSSION}

According to the research literature, the dysfunctional disorders caused by a heavy craniocerebral injury are manifested in the form of the acute renal insufficiency that develops as a result of the dience- 


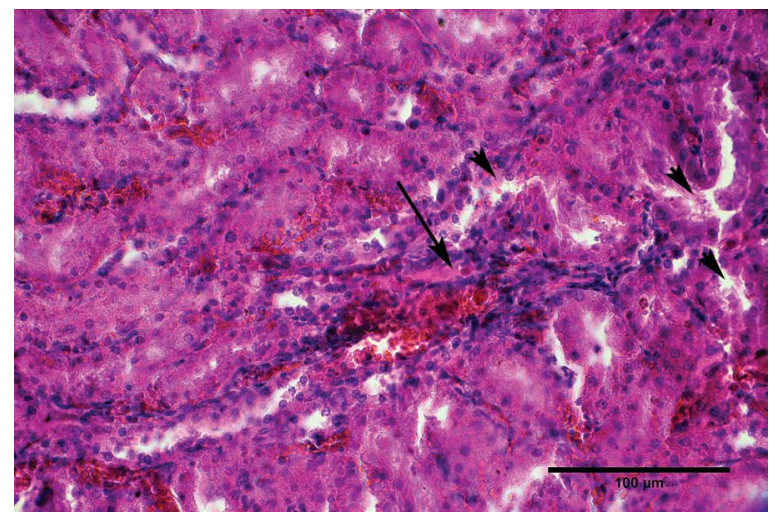

Figure 5. Perivascular infiltrate and sclerosis (arrow). Destruction of the renal tubules (arrowhead); $14^{\text {th }}$ day after traumatic brain injury; haematoxylin and eosin.

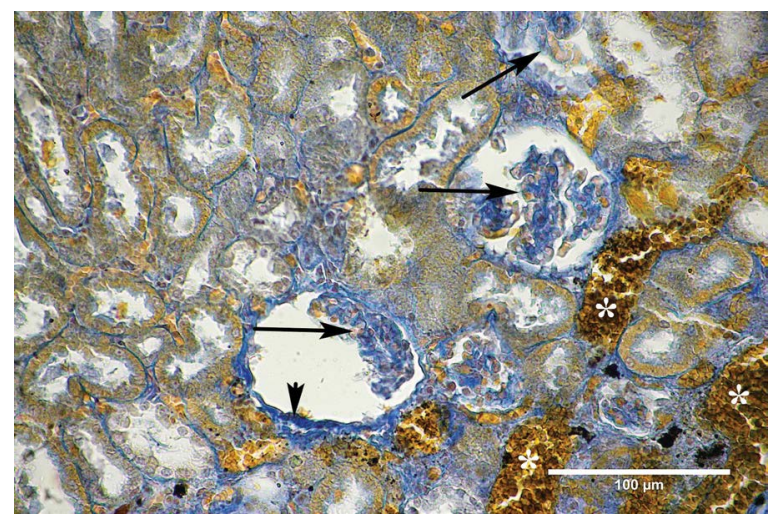

Figure 6. Fragmented renal glomeruli (arrow) with sclerosis (arrowhead) and blood stasis (asterisk); $21^{\text {st }}$ day after traumatic brain injury; trichrome.

phalic-catabolic syndrome $[4,5]$. In clinical treatment of patients with severe TBI described are dyscirculatory functional changes in the form of spasm of the arteries, arterioles, and venous plethora and diapedetic haemorrhages. In the future, this leads to metabolic, dystrophic, and necrotic changes. The first clinical sign of this is the appearance of red blood cells, protein, and cylinders in the urine.

The trigger mechanism of it could be, most likely, a massive adrenalin rush in the bloodstream with subsequent spasm of the microcirculatory bed that leads to the acute hepatorenal insufficiency. But such as complications is explained not only by the stress, but also by the activation of the cytokine system in response to brain damage leading to a systemic inflammatory response $[14,18]$. Due to a prolonged spasm and influence of catecholamines the signs of hypoxic damage of the vascular endothelium started to develop along with the formation of sludges and thrombi, increased endothelial permeability, and expression of endothelial adhesion molecules [18] which in the more prolonged periods of the experiment lead to the infarct of the renal parenchyma, destruction of the renal corpuscles, formation of sclerotic changes, and development of chronic renal insufficiency. The central dysregulation mechanisms after brain injury could contribute to the development and progression of extracerebral organ dysfunction by promoting systemic inflammation that may cause medical complications.

Microscopic studies of the kidneys in the first hour after the heavy TBI showed absolute dyscirculatory changes manifested by the spasm of vessels, congestion, and areas of the diapedesis haemorrhages on the border between the kidney cortex and the medulla $[1,15]$. On the $3^{\text {rd }}$ day after the injury, pathomorphological processes are complicated by the dystrophic and necrotic processes with manifestation of the ischaemic necrosis of the tubular epithelium and the interstitial oedema with disorganisation of the connective tissue $[1,15]$. In the case of the severe $\mathrm{TBI}$, observed were dyscirculatory changes in the liver, myocardium, and kidneys. They were accompanied by ischaemia, congestion, macrophagal and lymphocytic infiltration with dilatation of the vessels of various calibres, which in the more prolonged period after the TBI ( $5^{\text {th }}$ day) were complicated by the pathomorphological processes in the form of dystrophic and necrotic changes in all organs $[15,21]$.

In the course of this study, the following pattern in the development of pathological changes in the rats' kidneys resulting from the mild TBI was found: - on the $1^{\text {st }}-3^{\text {rd }}$ days, the development of mostly dyscirculatory changes manifested by the spasm of arterioles, dilatation of capillaries and venous bed were observed;

- on the $5^{\text {th }}-7^{\text {th }}$ days, the dyscirculatory changes are growing and are accompanied by the areas of destruction of the convoluted tubules and renal corpuscles. Such changes along with congestion and the areas of diapedesis and perivascular haemorrhages are best manifested between the cortex and medulla and in the areas close to the renal capsule. These pathological changes can explain the disorders of the filtration processes and urine reabsorption and are typical of the stage of the acute kidney failure;

- on the $14^{\text {th }}-21^{\text {st }}$ days, the intensity of the dyscirculatory and destructive changes decreases, 
although there are indications of the focal perivascular sclerosis, perivascular infiltrates and indications of sclerosis of some renal corpuscles.

In the context of the clinical application of the results of experimental studies of the effects of TBI on rats, it should be noted that a rat's kidney structurally and functionally has similarities to the human kidney. Minor differences are mainly at the macrostructural level; the rat kidney, unlike humans, contains one pyramid.

The structure of the vascular grid also differs. But nephron structure, hierarchy of kidney layers, and their functioning are similar as to those found in humans. This similarity allows us to make assumptions about the similarity of pathological changes caused by TBI. The limitation of full conclusions from the results of this work is its exclusively morphological character. For a full and voluminous conclusion, the physiological aspects of these changes also need to be investigated to evaluate a possible strategy for the treatment and prevention of urinary tract complications from TBI. However, the assured conclusion for the clinicians may be that attention is needed not only for patients with severe TBI but also those with mild head injuries as well. Particularly if mild TBI is part of the polytrauma, or if such patients have concomitant renal pathology.

\section{CONCLUSIONS}

Summarising the data from these experiments and considering the relevant reports contained in the research literature, it is reasonable to conclude that there is a clear dependence of developmental dynamics and notable degree of pathological changes in kidneys on the severity of the TBI. In case of a mild TBI, the greatest changes in the rats' kidneys appear on the $5^{\text {th }}-7^{\text {th }}$ days after the injury, which have a consistent tendency to decrease after that. However, morphological changes in the form of a perivascular sclerosis and focal changes in the renal corpuscles show the signs of a possible development of a chronic kidney failure even after a mild TBI.

\section{REFERENCES}

1. Aarabi B, Simard J. Traumatic brain injury. Curr Opin Crit Care. 2009; 15(6): 548-553, doi: 10.1097/mcc.0b013e32833190da.

2. Ahmed M, Sriganesh K, Vinay B, et al. Acute kidney injury in survivors of surgery for severe traumatic brain injury: Incidence, risk factors, and outcome from a tertiary neuroscience center in India. Br J Neurosurg. 2015; 29(4): 544-548, doi: 10.3109/02688697.2015.1016892, indexed in Pubmed: 25796992.
3. Bailes JE, Petraglia AL, Omalu BI, et al. Role of subconcussion in repetitive mild traumatic brain injury. J Neurosurg. 2013; 119(5): 1235-1245, doi: 10.3171/2013.7.JNS121822, indexed in Pubmed: 23971952.

4. Chepkiy L, Minov S, Chernyshov V. Pathogenesis, clinic, prognosis and prophylactics of poliorganic insufficiency at cranio-cerebral trauma. Ukr Neurosurgi J. 2011; 0(2): 56-59, doi: 10.25305/unj.57892.

5. Fursov I, Mogila V. Extracranial complications of severe head injury. Tavricheskiy Medico-Biol Vestn. 2013; 16: 146-149.

6. Guzeva V, Ochrim I, Maksimova N, et al. Characteristics of acute period of traumatic brain injury in children with hemophilia. Pediatrician (St. Petersburg). 2017; 8(3): 158-163, doi: 10.17816/ped83158-163.

7. Harting MT, Jimenez F, Adams SD, et al. Acute, regional inflammatory response after traumatic brain injury: Implications for cellular therapy. Surgery. 2008; 144(5): 803-813, doi: 10.1016/j.surg.2008.05.017, indexed in Pubmed: 19081024.

8. Heegaard W, Biros M. Traumatic brain injury. Emerg Med Clin North Am. 2007; 25(3): 655-78, viii, doi: 10.1016/j. emc.2007.07.001, indexed in Pubmed: 17826211.

9. Humphreys I, Wood RL, Phillips CJ, et al. The costs of traumatic brain injury: a literature review. Clinicoecon Outcomes Res. 2013; 5: 281-287, doi: 10.2147/CEOR. S44625, indexed in Pubmed: 23836998.

10. Kyrychenko A. Clinical and epidemiological aspects of primary disablement under craniocerebral trauma. Probl Ecol Med. 2012; 16: 30-33.

11. Lekhan V, Huk A. Specifics of traumatic brain injury epidemiology in aine. Ukr Nation's Health. 2010; 2: 7-14.

12. Li N, Zhao WG, Zhang WF. Acute kidney injury in patients with severe traumatic brain injury: implementation of the acute kidney injury network stage system. Neurocrit Care. 2011; 14(3): 377-381, doi: 10.1007/s12028-011-9511-1, indexed in Pubmed: 21298359.

13. Mascia L, Sakr Y, Pasero D, et al. Extracranial complications in patients with acute brain injury: a post-hoc analysis of the SOAP study. Intensive Care Med. 2008; 34(4): 720-727, doi: 10.1007/s00134-007-0974-7, indexed in Pubmed: 18175107.

14. McKeating EG, Andrews PJ, Signorini DF, et al. Transcranial cytokine gradients in patients requiring intensive care after acute brain injury. Br J Anaesth. 1997; 78(5): 520-523, doi: 10.1093/bja/78.5.520, indexed in Pubmed: 9175965.

15. Meretskyi V. Structural and morphological disorders of internal organs of rats with craniocerebral injury and diabetes mellitus. Hosp Surg. 2012: 56-60.

16. Meretskyi VM. Method for simulation of traumatic brain injury. 2012. http://uapatents.com/5-74935-sposib-modelyuvannya-cherepno-mozkovo-travmi.html.

17. Moore EM, Bellomo R, Nichol A, et al. The incidence of acute kidney injury in patients with traumatic brain injury. Ren Fail. 2010; 32(9): 1060-1065, doi: 10.3109/0886022X.2010.510234, indexed in Pubmed: 20863210

18. Ott L, McClain CJ, Gillespie M, et al. Cytokines and metabolic dysfunction after severe head injury. J Neurotrauma. 1994; 11(5): 447-472, doi: 10.1089/neu.1994.11.447, indexed in Pubmed: 7861440. 
19. Piek J, Chesnut RM, Marshall LF, et al. Extracranial complications of severe head injury. J Neurosurg. 1992; 77(6): 901-907, doi: 10.3171/jns.1992.77.6.0901, indexed in Pubmed: 1432133.

20. Pinto FC, Capone-Neto A, Prist R, et al. Volume replacement with lactated Ringer's or 3\% hypertonic saline solution during combined experimental hemorrhagic shock and traumatic brain injury. J Trauma. 2006; 60(4): 758-763, doi: 10.1097/01.ta.0000214581.89316.73, indexed in Pubmed: 16612295.

21. Puras U, Talypov A, Krylov V, et al. Factors of secondary ischemic cerebral damage at craniocerebral trauma. Part 1. Intracranial and extracranial factors of secondary cerebral damage. Russ Sklifosovsky J Emerg Med Care. 2012; 1: 56-65.

22. Semenova Z, Melnikov A, Savin I, et al. Recommendations for treatment of children with craniocerebral trauma. Russ J Pediatr Surg Anesth Intensive Care. 2016; 6: 112-127.
23. Skowronek R, Kobek M, Jankowski Z, et al. Traumatic basal subarachnoid haemorrhage or ruptured brain aneurysm in 16-year-old boy? — case report. Arch Med Sadowej Kryminol. 2016; 66(1): 32-40, doi: 10.5114/amsik.2016.62333, indexed in Pubmed: 28155987.

24. Tagliaferri F, Compagnone $C$, Korsic M, et al. A systematic review of brain injury epidemiology in Europe. Acta Neurochir (Wien). 2006; 148(3): 255-68; discussion 268, doi: 10.1007/ s00701-005-0651-y, indexed in Pubmed: 16311842.

25. Van Beek JGM, Mushkudiani NA, Steyerberg EW, et al. Prognostic value of admission laboratory parameters in traumatic brain injury: results from the IMPACT study. J Neurotrauma. 2007; 24(2): 315-328, doi: 10.1089/ neu.2006.0034, indexed in Pubmed: 17375996.

26. Verchère $J$, Blanot $S$, Vergnaud $E$, et al. Mortality in severe traumatic brain injury. Lancet Neurol. 2013; 12(5): 426-427, doi: 10.1016/S1474-4422(13)70073-5, indexed in Pubmed: 23602158. 